\title{
A Collaborative Study for the Determination of Tobacco Specific Nitrosamines in Tobacco*
}

\author{
by \\ Harold R. Burton ${ }^{3}$ \\ ${ }^{1}$ R.J. Reynolds Tobacco Company, Winston-Salem, North Carolina 27102, USA \\ ${ }^{2}$ U.S. Smokeless Tobacco Manufacturing LP, Nashville, Tennessee 37203, USA \\ ${ }^{3}$ University of Kentucky, Lexington Kentucky 40546, USA
}

Walter T. Morgan ${ }^{1}$, June B. Reece ${ }^{1}$, Charles H. Risner ${ }^{1}$, Cliff B. Bennett ${ }^{2}$, Carl H. Midgett ${ }^{2}$,Kathleen S. Johnson ${ }^{2}$, and

\section{SUMMARY}

The manuscript presents results from a collaborative study by 15 different laboratories using two different methods to determine tobacco specific nitrosamines (TSNAs) in tobacco and was performed under the auspices of the Tobacco Science Research Conference Analytical Methods Committee (TSRC-AMC). Although it is apparent that some of the laboratories failed to follow the provided protocols, both methods proved robust for determining TSNAs in a variety of different tobacco types. Twelve laboratories extracted the tobacco sample using an alkalinemethylene chloride extraction (Method 1) and nine used a buffer to extract the tobacco sample (Method 2). Six laboratories performed both methods. All participants used gas chromatography (GC) to separate the TSNAs and chemiluminescence detection. Method 1 used $N$-hexyl- $N$ nitroso-1-hexanamine (NDHA) as a surrogate (added prior to extraction) internal standard for quantitation. Method 2 used $N$-nitrosoguvacoline (NG) as the surrogate internal standard, NDHA as a chromatographic (added after extraction, prior to analysis) internal standard and external standard quantitation. After demonstrating that the average accuracy of both methods was at least about $92 \%$ through recovery studies, eight different tobacco types were analyzed in triplicate by each method. Means, reproducibility (precision between laboratories) and repeatability (precision within a laboratory) of results were determined for each method. After statistical analyses, it was established that both methods were capable of analyzing a variety of tobacco types and repeatability between methods was not significantly different. The limit of detection (LOD) and limit of quantitation (LOQ) were lower for Method 2 as compared to Method 1 when using the surrogate internal standard. Reproducibility variation, analyzed as the coefficient of variation, was $6 \%$ lower for Method 2 vs. Method 1 for $N$-nitrosonornicotine (NNN) and directionally $12 \%$ lower for 4-(methylnitrosamino)-1-(3-pyridyl)-1-butanone (NNK). Method 2 using NDHA as the chromatographic internal standard has been recommended by the TSRCAMC for use as a reference method. However, Method 1 using NDHA as surrogate internal standard is favored by four of the study participants because of lower chemical and material costs and higher sample throughput. [Beitr. Tabakforsch. Int. 21 (2004) 192-203]

\section{ZUSAMMENFASSUNG}

In dieser Arbeit werden die Ergebnisse eines Ringversuchs präsentiert, bei dem 15 verschiedene Labors auf der Basis zweier verschiedener Methoden und unter Leitung des für analytische Methoden verantwortlichen Ausschusses der „Tobacco Science Research Conference“ (TSRC-AMC) tabakspezifische Nitrosamine (TSNA) im Tabak bestimmt haben. Obwohl es offensichtlich ist, dass es einigen Labors nicht möglich war, dem Versuchsprotokoll zu entsprechen, haben sich dennoch beide Methoden für die Bestimmung der TSNAs bei einer Vielzahl unterschiedlicher Tabaksorten als geeignet erwiesen. Zwölf Labors extrahierten die Tabakprobe mit einer alkalischen Methylenchloridlösung (Methode 1) und neun mit einem Puffer (Methode 2). Sechs Labors führten beide Methoden durch. Die TSNAs wurden von allen Teilnehmern mittels Gaschromatographie (GC) getrennt und durch Chemilumineszenz detektiert. Bei der Methode 1 wurde $N$-Hexyl- $N$-nitroso-1-hexanamin (NDHA) als interner Surrogat-Standard (vor der Extraktion hinzugefügt) zur Quantifizierung verwendet. Bei der

*Received: $21^{\text {st }}$ February - accepted: $15^{\text {th }}$ May 2004 
Methode 2 wurde $N$-Nitrosoguvacolin (NG) als interner Surrogat-Standard und NDHA als interner chromatographischer Standard (nach der Extraktion und vor der Analyse hinzugefügt) verwendet sowie mittels externem Standard quantifiziert. Nachdem in Wiederfindungsuntersuchungen gezeigt wurde, dass die durchschnittliche Richtigkeit beider Methoden bei mindestens $92 \%$ lag, wurden acht verschiedene Tabaksorten mit jeder Methode dreifach untersucht. Die Mittelwerte, die Reproduzierbarkeit (Präzision der Messergebnisse zwischen den Labors) und die Wiederholbarkeit (Präzision der Messergebnisse innerhalb eines Labors) wurden für jede Methode bestimmt. Nach der statistischen Auswertung wurde festgestellt, dass beide Methoden dazu geeignet sind, verschiedene Tabaksorten zu analysieren und dass die Wiederholbarkeit beider Methoden nicht signifikant verschieden ist. Die Nachweisgrenze (LOD) und die Quantifizierungsgrenze (LOQ) waren bei Verwendung des internen Surrogat-Standards bei der Methode 2 niedriger als bei Methode 1. Die Reproduzierbarkeit, gemessen als Variationskoeffizient, war für $N$ Nitrosonornikotin (NNN) bei Methode 2 im Vergleich zu Methode 1 um 6\% und für 4-(Methylnitrosamino)-1-(3pyridyl)-1-butanon (NNK) um $12 \%$ niedriger. Die Methode 2 , bei der NDHA als interner chromatographischer Standard verwendet wird, wurde vom Ausschuss TSRC-AMC als Referenzmethode empfohlen. Die Methode 1, bei der NDHA als interner Surrogat-Standard verwendet wurde, wird jedoch von vier Ringversuchsteilnehmern aufgrund der niedrigeren Kosten für chemische Substanzen und Material sowie dem größeren Probendurchsatz bevorzugt. [Beitr. Tabakforsch. Int. 21 (2004) 192-203]

\section{RESUME}

Les résultats d'une étude collective où la teneur en nitrosamines spécifiques du tabac (TSNA) a été dosée dans le tabac par 15 laboratoires différents utilisant deux méthodes différentes sous les auspices du Comité des Méthodes Analytiques de la «Tobacco Science Research Conference », sont présentés. Bien qu'il soit évident que quelquesuns des laboratoires ne soient pas parvenus à suivre le protocole, les deux méthodes se sont révélées robustes pour le dosage des TSNAs dans différents types de tabacs. Douze laboratoires ont extrait l'échantillon de tabac par du chlorure de méthylène alcalin (Méthode 1) et neuf laboratoires ont extrait l'échantillon avec une solution tampon (Méthode 2). Six laboratoires ont employé les deux méthodes. Dans tous les laboratoires les TSNAs ont été séparés par chromatographie en phase gazeuse (GC) et identifiés par chimiluminescence. Dans la méthode 1 , le $N$-hexyl- $N$ nitroso-1-hexanamine (NDHA) a été utilisé comme standard interne de substitution (ajouté avant l'extraction) pour la quantification. Dans la méthode 2, le $N$-nitrosoguvacoline (NG) a été utilisé comme standard interne de substitution, le NDHA a été utilisé comme standard interne chromatographique (ajouté après l'extraction et avant l'analyse) et quantifié par le standard externe. Après avoir montré dans des études de récupération que la précision des deux méthodes est au moins de $92 \%$, huit différents types de tabac ont été analysés en trois répétitions pour chacune des méthodes. La moyenne, la reproductibilité (précision parmi les laboratoires) et la répétabilité (précision au sein d'un laboratoire) des résultats ont été déterminées pour chaque méthode. Après analyses statistiques, il a été établi que les deux méthodes permettent l'analyse de divers types de tabac et que la répétabilité des deux méthodes n'est pas significativement différente. La limite de détection (LOD) et la limite de quantification (LOQ) sont plus faibles avec la méthode 2 qu'avec la méthode 1 dans le cas du standard interne de substitution. La variation de la reproductibilité, analysée comme coefficient de variation, est de $6 \%$ plus faible avec la méthode 2 par rapport à la méthode 1 pour le $N$-nitrosonornicotine (NNN) et de $12 \%$ plus faible avec le 4-(methylnitrosamino)-1-(3-pyridyl)-1-butanone (NNK). La méthode 2 utilisant le NDHA comme standard interne chromatographique a été recommandée par la commission TSRC-AMC comme méthode de référence. Cependant, la méthode 1 avec NDHA comme standard de substitution est recommandée par quatre participants de l'étude en raison du coût des produits chimiques, du matériel réduit et d'un nombre d'échantillons traités plus importants. [Beitr. Tabakforsch. Int. 21 (2004) 192-203]

\section{INTRODUCTION}

Four of the most prevalent $N$-nitrosamines in tobacco and tobacco smoke are $N$-nitrosonornicotine (NNN), $N$-nitrosoanatabine (NAT), $N$-nitrosoanabasine (NAB), and 4(methylnitrosamino)-1-(3-pyridyl)-1-butanone (NNK). These four $N$-nitrosamines are usually classified as tobacco specific nitrosamines (TSNAs).

With the ongoing interest in TSNAs in tobacco, analytical methods for TSNAs are constantly being developed and improved. Due to the efforts of the tobacco industry to reduce TSNAs in cured tobacco leaf, many laboratories have expanded their operations to handle the increasing workload. This has led to a proliferation of procedures and inconsistencies when results from different laboratories are compared. The Tobacco Science Research Conference Analytical Methods Committee ( TSRC-AMC) coordinated an inter-laboratory collaborative study to establish a method for the analysis of TSNAs in tobacco that is acceptable as a benchmark procedure.

In December of 1999, an invitation was extended to potential participants to take part in a collaborative study. The collaborative study objectives were to be accomplished in three phases. The first phase was to compare the TSNAs analysis procedures currently in practice. The second phase was to identify, by consensus of participants, a suitable methodology(s) to be used in a collaborative study. The third phase was to conduct a collaborative testing study using the selected procedure(s). Seventeen laboratories participated in the first part of the collaborative study. All laboratories, with the exception of one, used gas chromatography (GC) with a capillary column to separate the TSNAs and chemiluminescence to detect the compounds. The one exception used high performance liquid chromatography for TSNA separation with mass spectral detection (1). This laboratory was also unique among all laboratories in that it used solid phase extraction to prepare the sample that was extracted into a buffer solution (1). Six laboratories used a common method 
consisting of buffer extraction and the use of diatomaceous earth for sample preparation and water removal (2). The procedures differed between these six laboratories only by method of quantification. Two laboratories used internal standards and the other four used external standards for quantification. Four laboratories used a common procedure consisting of aqueous alkaline extraction, diatomaceous earth/ascorbic acid sample preparation and quantification based on an internal standard (3). Two laboratories followed the procedure described in reference 3 precisely. One laboratory modified the method by using a different internal standard. One laboratory performed the same procedure, but used external standards for quantification. Another laboratory used supercritical fluid extraction to extract the tobacco, isolation of the TSNAs on a Tenax ${ }^{\mathrm{TM}}$ trap, elution of the TSNAs from the trap with methylene chloride $\left(\mathrm{MeCl}_{2}\right)$ and quantification using an internal standard $(4,5,6)$. Three participants used a common procedure consisting of alkaline $\mathrm{MeCl}_{2}$ extraction, a column containing sulfate salts for sample preparation/water removal, elution of the TSNAs using $\mathrm{MeCl}_{2}$ and quantification by internal standard (7). Two unpublished procedures were performed. One consisted of extracting the tobacco in $\mathrm{MeCl}_{2}$, acid washing the extract, back extracting the TSNAs into $\mathrm{MeCl}_{2}$ after a $\mathrm{pH}$ adjustment and the use of two internal standards for quantification. The other unpublished procedure extracted the tobacco in $\mathrm{MeCl}_{2}$, used alumina for sample preparation and quantitated with an internal standard.

These seven different procedures varied not only as described above, but also in sample size, extraction time, extract preparation, means of concentrating the extract, the internal standard used and the point at which the internal standard was added in the sample preparation scheme. Various GC columns and conditions and chemiluminescence detector settings were also used. More detail on these procedures can be found in reference 8 .

The participants were asked to perform their procedures for the analyses of six different tobacco sample types, in replicates of four on three different days. The six tobacco samples and TSNA standards were distributed to all participants by a single laboratory. The results between laboratories in this study were quite variable (8).

Upon review of the study results, two methods were selected by participants, for further comparative investigations in the third phase of the study. Method 1, entitled "Quantification of Tobacco Specific Nitrosamines in Tobacco Using Alkaline Methylene Chloride Extraction", was chosen based on having the best reproducibility and lowest within-day standard deviation. Method 1 was also appealing to many laboratories since it used a minimal amount of solvent, did not require a large capital investment to perform the extraction and had a high sample throughput. Method 1 was performed using robotics in the initial study. The procedure was modified to be conducted manually in the subsequent collaborative study. Method 2, entitled "Quantification of Tobacco Specific Nitrosamines in Tobacco Using Buffer Extraction" was chosen because many of the participants currently practice the procedure. Method 2 was modified to be able to quantitate results by surrogate internal standard $N$-nitrosoguvacoline (NG), chromatographic internal standard $N$-hexyl- $N$-nitroso-1- hexanamine (NDHA) and external standard methods. The internal standard modifications to Method 2 were made to determine if surrogate or chromatographic internal standards were needed, since higher results were obtained when internal standards were used in the initial study (8). This work describes the results obtained when comparing these two procedures.

\section{EXPERIMENTAL}

\section{Method 1: Chemicals and reagents}

Nitrosamines are suspected carcinogens; therefore, appropriate safety precautions should be taken when preparing these standards. Appropriate gloves should be worn when handling standard solutions and making dilutions.

NNN, NAT, NAB and NNK were obtained from NCI Chemical Carcinogen Reference Standard Repository. NDHA (surrogate internal standard) was obtained from Qventas, Inc. The TSNAs and NDHA of the same lot were procured by a single laboratory and distributed to the participants. Magnesium sulfate (anhydrous), EM Science brand was obtained from VWR Scientific. Sodium sulfate (anhydrous) and sodium hydroxide $(\mathrm{NaOH}$, pellets) were obtained from Fisher Scientific. $\mathrm{MeCl}_{2}$ and chloroform were purchased from Burdick \& Jackson. Nicotine (Fluka brand) was purchased from Sigma. Oxygen (grade 4.4) and helium were supplied by BOC Gases. Water (distilled and deionized, $\mathrm{D}^{2} \mathrm{H}_{2} \mathrm{O}$ ) was specified to have a conductivity of 17.5 megohm cm${ }^{-1}$ or greater.

\section{Method 1: Equipment and apparatus}

A Hewlett Packard model 5890 gas chromatograph was equipped with a Thermo Orion Model 543 Thermal Energy Analyzer chemiluminescence detector. A Restek $4 \mathrm{~mm}$ i.d. split sleeve liner containing glass wool was used in the injection port. The GC column (J \& W Scientific Co.) was a DB-5, $30 \mathrm{~m} \times 0.53 \mathrm{~mm}$ i.d. with a $1.5 \mu \mathrm{m}$ film thickness. Samples and reagents were weighed on a Mettler AE 240 analytical balance. Sample extracts were concentrated using an Organomation Associates model 111 analytical evaporator and agitated using a Thermolyne Maxi Mix II type 37600 mixer/vortexer. Class A volumetric flasks and disposable glass transfer pipettes for handling small volumes of liquid were used. The extracting solution was dispensed using a $10-\mathrm{mL}$ volumetric delivery head from Markson. Threaded top test tubes used during extraction were $20 \times 150 \mathrm{~mm}$ which accepted an 18-415 thread test tube cap (Fisher Scientific). Test tubes used for concentration $(16 \times 100 \mathrm{~mm})$ and the blank extraction columns with frits (PrepSep -R, 14-mL volume) were also purchased from Fisher Scientific. GC vials were $2 \mathrm{~mL}$ in volume and used screw-top Teflon ${ }^{\mathrm{TM}}$ caps.

\section{Method 1: Tobacco samples}

Low TSNAs flue-cured (heat exchange cured), flue-cured (non-heat exchange cured), Turkish, burley and burley stems were obtained from the same source. The 1R4F reference cigarette tobacco blend and $2 \mathrm{~S} 3$ reference moist 


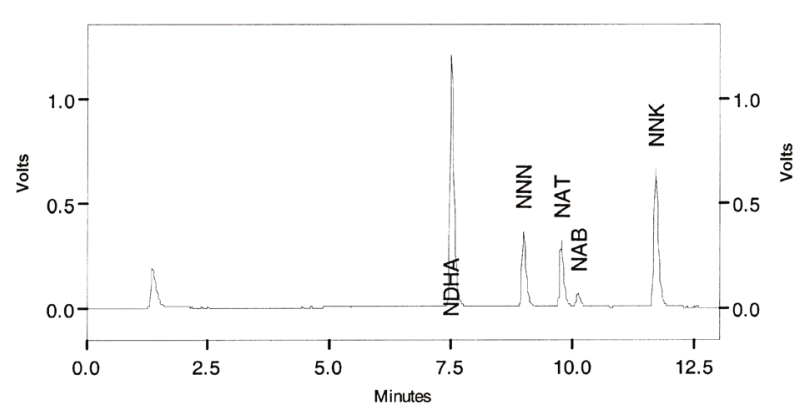

Figure 1. Gas chromatogram of a standard using Method 1 (Conditions: see Experimental section)

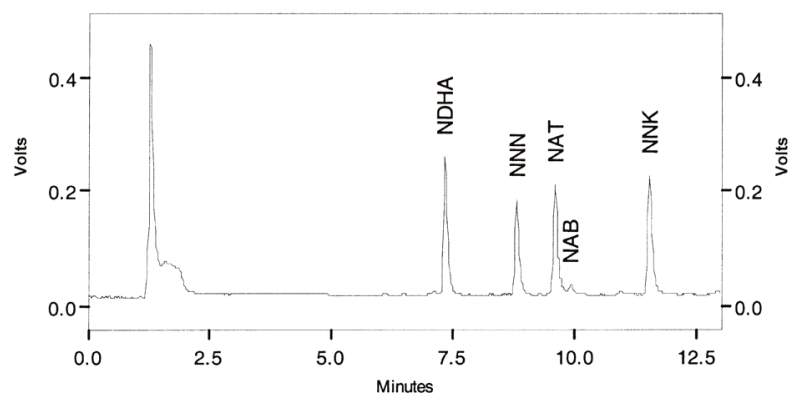

Figure 2. Gas chromatogram of a flue-cured tobacco extract using Method 1 (Conditions: see Experimental section)

snuff was obtained from the Tobacco and Health Research Institute, Lexington, Kentucky. A commercial composite tobacco blend used in the manufacture of light cigarettes was prepared by blending cut tobacco fillers supplied by four cigarette manufacturers. All samples were ground to a mesh size of approximately 40 except for the 1R4F reference cigarette tobacco blend, which was supplied in the form of a pack of cigarettes. These samples were chosen to represent several categories of tobacco presently in use and to supply participants with samples having a wide range of concentrations of TSNAs for analysis. All samples were distributed by the same laboratory.

\section{Method 1: Preparation of solutions and standards}

1) The $10 \% \mathrm{w} / \mathrm{w}$ solution of $\mathrm{NaOH}$ was prepared by weighing about $10 \mathrm{~g} \mathrm{NaOH}$ pellets into a $100-\mathrm{mL}$ beaker. $\mathrm{D}^{2} \mathrm{H}_{2} \mathrm{O}$ was added to a total weight of $100 \mathrm{~g}$ and stirred until dissolved.

2) The surrogate internal standard stock solution was prepared by dissolving NDHA in $\mathrm{MeCl}_{2}$ to yield a concentration of about $200 \mu \mathrm{g}$ NDHA mL ${ }^{-1}$. This stock solution was further diluted such that the concentration of NDHA was $0.40 \mu \mathrm{g} \mathrm{mL}^{-1}$. This diluted solution in $\mathrm{MeCl}_{2}$ was used as part of the extractant (see Sample preparation). All solutions of the surrogate internal standard were stored in a freezer when not in use.

3) A standard dilution solution was prepared by dissolving nicotine in chloroform to attain a concentration of $60 \mu \mathrm{L}$ nicotine $\mathrm{mL}^{-1}$.

4) Calibration standards were prepared by dissolving NDHA, NNN and NNK in chloroform to prepare stock solutions. NAT and NAB were supplied as stock solutions in isopropanol at specified concentrations. Based on a preliminary analysis of the eight tobacco samples, the TSNAs were serially diluted using the standard dilution solution to at least four levels to span the concentration range of the samples. The NDHA concentration in the calibration standards was $5.0 \mu \mathrm{g} \mathrm{mL}^{-1}$. All solutions of the calibration standards were stored at $4{ }^{\circ} \mathrm{C}$ when not in use.

\section{Method 1: GC and detector conditions}

The helium flow was set at $5.66 \mathrm{~mL} \mathrm{m^{-1 }}$. Splitless injection was performed using a $2 \mu \mathrm{L}$ injection volume into the injector which was set at $210{ }^{\circ} \mathrm{C}$. The initial oven temperature was set at $100{ }^{\circ} \mathrm{C}$ and ramped at $6{ }^{\circ} \mathrm{C} \mathrm{min}{ }^{-1}$ to a $240{ }^{\circ} \mathrm{C}$ final oven temperature. The total run time was approximately $23 \mathrm{~min}$ and equilibration time was $3 \mathrm{~min}$. Approximately five inches of the capillary GC column was inserted directly into the ceramic pyrolyzer tube of the detector. The detector interface temperature was $250{ }^{\circ} \mathrm{C}$ and the pyrolyzer temperature was $550^{\circ} \mathrm{C}$. The inlet purge was turned on at $2.5 \mathrm{~min}$ and turned off after $20 \mathrm{~min}$.

Figure 1 is a chromatogram of a standard analyzed under these conditions.

\section{Method 1: Sample preparation}

1) Each tobacco sample, about $1.5 \mathrm{~g}$, was weighed accurately into a $20 \times 150 \mathrm{~mm}$ test tube and capped.

2) Empty fritted extraction columns were filled with an approximately 0.25 inch $(0.4 \mathrm{~cm}$, about $0.75 \mathrm{~g})$ layer of anhydrous sodium sulfate followed by an approximately 1.25 inch $(3.5 \mathrm{~cm}$, about $2.5 \mathrm{~g})$ layer of anhydrous magnesium sulfate.

3) The extraction solution consisting of $10 \mathrm{~mL}$ of $0.40 \mu \mathrm{g}$ $\mathrm{mL}^{-1} \mathrm{NDHA}$ in $\mathrm{MeCl}_{2}$ was dispensed into the test tube followed by the addition of $0.5 \mathrm{~mL}$ of $10 \% \mathrm{w} / \mathrm{w} \mathrm{NaOH}$.

4) The test tube containing the sample was vortexed twice for $90 \mathrm{~s}$ and allowed to stand 20 min between each vortexing. The test tube was then vortexed a third time for $60 \mathrm{~s}$ and the liquid portion of the test tube contents was decanted onto the prepared extraction column.

5) The eluent was collected in a $16 \times 100 \mathrm{~mm}$ test tube. The extraction column was rinsed with $2 \mathrm{~mL}$ of $\mathrm{MeCl}_{2}$ which was also collected in the test tube.

6) The collection tube containing the eluent was placed in an evaporator and dried at $42{ }^{\circ} \mathrm{C}$ for $40 \mathrm{~min}$ using air to facilitate the evaporation.

7) The evaporated extract residue was reconstituted in about $0.7 \mathrm{~mL}$ of chloroform and vortexed. The extract was then transferred to a GC vial and capped. Figure 2 is a chromatogram of a flue-cured tobacco extract using the conditions described for Method 1.

\section{Method 1: Participant deviations from the method}

Of the twelve laboratories which performed Method 1, three did not use nicotine in the calibration standards and two diluted the calibration standards in $\mathrm{MeCl}_{2}$ rather than chloroform. One laboratory used a concentration of $4.0 \mu \mathrm{g}$ NDHA $\mathrm{mL}^{-1}$ in the calibration standard and one extracted the samples in $10 \mathrm{~mL}$ of $0.50 \mu \mathrm{g}$ NDHA $\mathrm{mL}^{-1}$ rather than the specified concentration of $0.40 \mu \mathrm{g}$ NDHA $\mathrm{mL}^{-1}$. One 


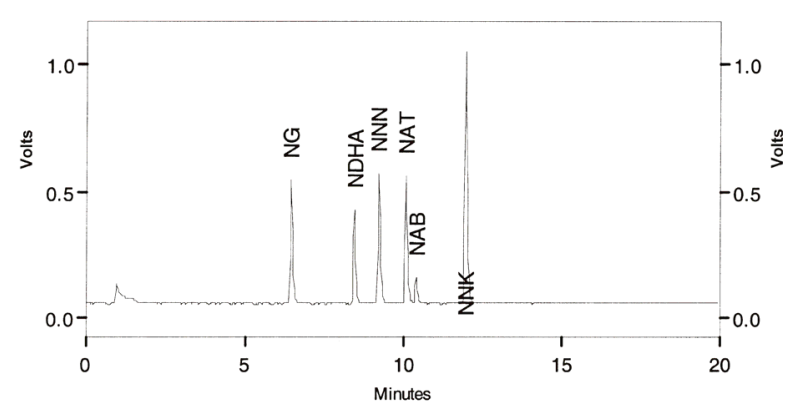

Figure 3. Gas chromatogram of a standard using Method 2 (Conditions: see Experimental section)

laboratory used an Antek chemiluminescence detector. One participant used a $15 \mathrm{~m} \mathrm{DB}-5$ capillary column. In one instance, the sample extract was vortexed 5 min and then centrifuged for $30 \mathrm{~min}$ at $2500 \mathrm{rpm}$ prior to decanting onto the extraction column.

\section{Method 2: Chemicals and reagents (other than those specified in Method 1)}

NG (surrogate internal standard) was obtained from International Specialty Chemicals, Inc. Citric acid (anhydrous) and dibasic sodium phosphate (anhydrous) were purchased from Sigma. L-Ascorbic acid was procured from Aldrich. Nitrogen (grade 5.9+) was supplied by BOC Gases.

\section{Method 2: Equipment and apparatus (other than those specified in Method 1)}

A Hewlett-Packard split liner was used in the split/splitless injection port. The GC column was a DB-1 from J \& W Scientific Co., $30 \mathrm{~m} \times 0.53 \mathrm{~mm}$ i.d. with a $3.0 \mu \mathrm{m}$ film thickness. A Zymark TurboVap II Workstation was used to concentrate the extract. A Zymark 200-mL capacity sampling tube with a $0.5 \mathrm{~mL}$ stem was used to collect the eluent. A Branson Model 8510 ultrasonic bath was used for extraction of samples. Varian Chem Elut tubes of 100-mL sample capacity were used to remove water from the sample extracts. Markson volumetric delivery heads of 10and $50-\mathrm{mL}$ were used to dispense the buffer extracting solution. Samples were weighed into $125 \mathrm{~mL}$ Erlenmeyer flasks and $250 \mathrm{~mL}$ graduated cylinders were used to add $\mathrm{MeCl}_{2}$ to the Chem Elut tubes.

\section{Method 2: Tobacco samples}

Tobacco samples were the same as described in Method 1.

\section{Method 2: Preparation of solutions and standards}

1) Two liters of buffer solution used for extraction of the samples was prepared by weighing $21.1 \mathrm{~g}$ citric acid, 25.6 $\mathrm{g} \mathrm{Na}_{2} \mathrm{HPO}_{4}$ and $7.0 \mathrm{~g} \mathrm{~L}$-ascorbic acid $( \pm 0.1 \mathrm{~g})$ into a $2-\mathrm{L}$ volumetric flask. $\mathrm{D}^{2} \mathrm{H}_{2} \mathrm{O}$ water was added to the mark and the contents mixed until all solids were dissolved. The buffer solution was prepared weekly and refrigerated when not in use. The buffer extraction solution was clear and colorless with a $\mathrm{pH}$ of about 4.3.
2) The surrogate internal standard stock solution was prepared by dissolving $\mathrm{NG}$ in $\mathrm{MeCl}_{2}$ to yield a concentration of approximately $200 \mu \mathrm{g} \mathrm{NG} \mathrm{mL}{ }^{-1}$. This stock solution was further diluted such that the concentration of $\mathrm{NG}$ was $2.0 \mu \mathrm{g} \mathrm{mL}^{-1}$. This diluted solution in $\mathrm{MeCl}_{2}$ was used as part of the extractant (see Sample preparation). All solutions of the surrogate internal standard were stored in a freezer when not in use.

3) The chromatographic internal standard stock solution was prepared by dissolving NDHA in $\mathrm{MeCl}_{2}$ to yield a concentration of approximately $200 \mu \mathrm{g} \mathrm{NDHA} \mathrm{mL}^{-1}$. This stock solution was further diluted such that the concentration of NDHA was $2.0 \mu \mathrm{g} \mathrm{mL}^{-1}$. This diluted solution in $\mathrm{MeCl}_{2}$ was added to the $\mathrm{MeCl}_{2}$ eluent of the Chem Elut tubes (see Sample preparation). All solutions of the chromatographic internal standard were stored in a freezer when not in use.

4) Calibration standards were prepared by dissolving NDHA, NNN and NNK in $\mathrm{MeCl}_{2}$ to prepare stock solutions. NAT and NAB were supplied as stock solutions in isopropanol at specified concentrations. Based on a preliminary analysis of the eight tobacco samples, the TSNAs were serially diluted using $\mathrm{MeCl}_{2}$ to at least four levels to span the concentration range of the samples. The NG and NDHA concentrations in the calibration standards were 1.0 $\mu \mathrm{g} \mathrm{mL}^{-1}$. All solutions of the TSNAs calibration standards were stored in a freezer when not in use.

\section{Method 2: GC and detector conditions}

Helium pressure was set at $7.0 \mathrm{psi}$. Splitless injection was performed using a $2 \mu \mathrm{L}$ injection volume into the injector which was set at $230{ }^{\circ} \mathrm{C}$. The initial oven temperature was set at $100{ }^{\circ} \mathrm{C}$ and held for $1 \mathrm{~min}$. The temperature was ramped $30{ }^{\circ} \mathrm{C} \mathrm{min}{ }^{-1}$ to $200{ }^{\circ} \mathrm{C}$ then to $235^{\circ} \mathrm{C}$ using a ramp of $3{ }^{\circ} \mathrm{C} \mathrm{min}{ }^{-1}$ and finally to a temperature of $260{ }^{\circ} \mathrm{C}$ at $30{ }^{\circ} \mathrm{C} \mathrm{min}{ }^{-1}$. The total run time was approximately $25 \mathrm{~min}$. A length of uncoated capillary tubing, $150 \mathrm{~cm}$ of $0.25 \mathrm{~mm}$ i.d., was used to connect the end of the analytical column to the detector to balance the gas pressure of the vacuum pump on the detector with the gas pressure exiting from the analytical column. The uncoated capillary tubing was inserted through the furnace and attached to the inlet of the detector. Connections to the analytical column were made with universal press-tight connectors. The detector interface temperature was $275{ }^{\circ} \mathrm{C}$ and the pyrolyzer temperature was $500{ }^{\circ} \mathrm{C}$. The ozone flow to the detector was approximately $5.1 \mathrm{cc} \mathrm{min}^{-1}$. The inlet purge was turned on at $0.6 \mathrm{~min}$ and then set to 50:1 thereafter. Figure 3 is a chromatogram of a standard analyzed under these conditions.

\section{Method 2: Sample preparation}

1) The tobacco sample, about $1.0 \mathrm{~g}$, was weighed accurately into a $125-\mathrm{mL}$ Erlenmeyer flask and $1 \mathrm{~mL}$ of $2.0 \mu \mathrm{g}$ $\mathrm{mL}^{-1}$ of $\mathrm{NG}$ in $\mathrm{MeCl}_{2}$ (surrogate internal standard) was added prior to the addition of $50 \mathrm{~mL}$ of the buffer extracting solution.

2) The flask was covered with a glass stopper, sonicated for $1 \mathrm{~h}$ and allowed to cool $10 \mathrm{~min}$. (The water in the sonicator should not exceed $40{ }^{\circ} \mathrm{C}$ ). 


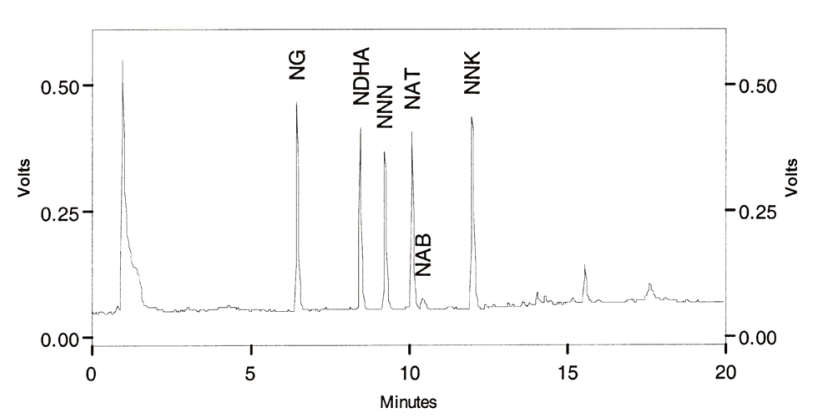

Figure 4. Gas chromatogram of a flue-cured tobacco sample extract using Method 2 (Conditions: see Experimental section)

3) A 100-mL water capacity Chem Elut column was assembled above a $200 \mathrm{~mL}$ Zymark sampling tube with a $0.5 \mathrm{~mL}$ stem.

4) After sonication, the contents of the extraction flask were poured onto the head of the Chem Elut column. The flask was rinsed with $10 \mathrm{~mL}$ of buffer and the contents again poured onto the head of the column.

5) After the liquid had permeated one-third the length of the column and no liquid was standing at the head of the column, a $150 \mathrm{~mL}$ portion of $\mathrm{MeCl}_{2}$ was added and allowed to penetrate the column until about $20 \mathrm{~mL}$ of liquid was visible above the solid surface of the column (the column was not allowed to become dry). At this time, a second $150 \mathrm{~mL}$ of $\mathrm{MeCl}_{2}$ was poured on the column. The $\mathrm{MeCl}_{2}$ was allowed to pass through the column (about $1 \mathrm{~h}$ ) and was collected into a 200-mL Zymark sampling tube. The elution process was considered complete when the flow of $\mathrm{MeCl}_{2}$ from the column slowed to less than one drop in ten seconds and about $250 \mathrm{~mL}$ of eluent had been collected. One milliliter of $2.0 \mu \mathrm{g} \mathrm{mL}^{-1} \mathrm{NDHA}$ in $\mathrm{MeCl}_{2}$ (chromatographic internal standard) was then added to the collected eluent.

6) The sample tube containing the eluent was placed in the TurboVap Concentrator whose water bath was preheated to $38^{\circ} \mathrm{C}$. The pressure of the nitrogen gas flow was increased gradually to create a vortex in the liquid. The sample extract was concentrated to about $0.5 \mathrm{~mL}$ after which the sampling tube was removed from the apparatus.

7) The contents of the sampling tube was transferred to a 2-mL volumetric flask. Two $0.5 \mathrm{~mL}$ portions of $\mathrm{MeCl}_{2}$ were used to rinse the sampling tube and the rinses were added to the 2-mL volumetric flask. The sample was diluted to a final volume of $2 \mathrm{~mL}$ with $\mathrm{MeCl}_{2}$. A portion was transferred to a GC vial and capped.

Figure 4 is a chromatogram of a flue-cured tobacco extract using the conditions described for Method 2.

\section{Method 2: Participant deviations from the method}

Three participants used J \& W Scientific DB-5 capillary columns, two used $30 \mathrm{~m}$ columns and one used a $15 \mathrm{~m}$ column. Two laboratories did not use an uncoated section of capillary tubing to connect the end of the analytical column to the detector, but rather connected the analytical column directly to the pyrolyzer tube of the detector. Two participants used direct on-column injection and two evaporated the $\mathrm{MeCl}_{2}$ eluent using a Buchi Rotovapor evaporator. One laboratory increased the concentration of the internal standards to $4.7 \mu \mathrm{g} \mathrm{mL}^{-1} \mathrm{NG}$ and $5.0 \mu \mathrm{g} \mathrm{mL}^{-1}$ NDHA and diluted the extract to a final volume of $1 \mathrm{~mL}$. One laboratory used an Antek chemiluminescence detector.

\section{COLLABORATIVE PROTOCOL}

Detailed procedures in the form of a protocol were supplied to the fifteen laboratories participating in the collaborative study. Twelve laboratories conducted Method 1 and nine performed Method 2. Six laboratories conducted both methods. Laboratories not experienced in performing the procedures were provided samples used in a previous part of the collaborative study to practice the procedures and compare their results. The participants were supplied with approximately $100 \mathrm{~g}$ of the eight different tobacco sample types (see Experimental section) and were asked to analyze each sample in triplicate. These analyses were to be conducted on different days for the different samples, but the three replicates of the same tobacco type were to be analyzed on the same day. The sample extracts were to be injected twice and analyzed by the same operator using the same equipment and quantified using the same calibration. Method 1 results accounted for 720 data points and Method 2 for 432 data points for each variation of quantification. The participants were asked to submit results in a Microsoft Excel $^{\mathrm{TM}}$ spread sheet format. Percent oven volatiles were determined by each participant and results were corrected for moisture by each laboratory.

\section{STATISTICAL METHODS}

Analysis of data collected generally followed statistical procedures described in the International Organization for Standardization (ISO) document 5725-2 (9). This document describes techniques for detection of outlier values, estimation of sample mean values, and estimation of repeatability and reproducibility standard deviations for each sample. Detection of outliers was performed using Mandel charts, Cochran's test, and Grubbs' test. Mandel charts are graphs of the normalized mean and sample standard deviation values with lines indicating statistically significant outlier laboratories. These charts identify laboratories with consistent outliers for the entire range of samples. All data from a laboratory may be excluded if the analyst judges that a laboratory is consistently different from the others, although the standard does not specify rules for making this determination. ISO 5725-2 does, however, specify a procedure for applying Cochran's test (for identifying laboratories with significantly greater variability than the other laboratories), and Grubbs' test (for identifying laboratories with means which are significantly different from the other laboratories) in sequence, with multiple iterations. These tests were applied independently for each sample, with values for which $0.01<p$ $<0.05$ were identified as stragglers (unusual values but retained for analysis), and values for which $p<0.01$ were identified as outliers (excluded from further analysis). Repeatability standard deviation is an estimate of variability among replicates run under controlled conditions in the same laboratory (estimated by pooling standard deviation 
Table 1. Percent recovery results of TSNAs determined using three different tobaccos analyzed in triplicate at three concentration levels of TSNAs

\begin{tabular}{|c|c|c|c|c|c|c|}
\hline \multirow[b]{2}{*}{ Method } & \multirow{2}{*}{$\begin{array}{c}\text { Overall } \\
\text { mean }\end{array}$} & \multicolumn{4}{|c|}{ Nitrosamine } & \multirow{2}{*}{$\begin{array}{c}\text { Method of } \\
\text { quantification } \\
\end{array}$} \\
\hline & & NNN & NAT & NAB & NNK & \\
\hline $1^{b}$ & 92.1 & 97.0 & 94.8 & 85.5 & 91.3 & NDHA S.I.S. \\
\hline $2^{c}$ & 91.6 & 92.2 & 88.5 & 94.7 & 91.0 & E.S. \\
\hline $2^{b}$ & 99.6 & 100.0 & 93.3 & 109.2 & 96.0 & NG S.I.S. \\
\hline $2^{b}$ & 97.0 & 93.4 & 92.1 & 106.8 & 95.8 & NDHA C.I.S. \\
\hline
\end{tabular}

${ }^{a}$ Abbreviations: S.I.S. = surrogate internal standard; E.S. = external standard; C.I.S. = chromatographic internal standard.

${ }^{\mathrm{b}}$ Standards in $\mathrm{MeCl}_{2}$ added to tobacco.

${ }^{\circ}$ Standards in buffer added to tobacco.

estimates across laboratories), while reproducibility standard deviation is an estimate of variability among replicates run at different laboratories. These quantities were estimated for each sample after the exclusion of outliers.

In the collaborative study, each laboratory was asked to run duplicate injections for each of three extractions for each sample (six determinations per sample). Data from laboratories for which fewer than four determinations were available were excluded for that sample (results below the limit of quantitation were observed in some cases). Before starting the ISO 5725-2 collaborative study procedure described above, Cochran's test was used to compare the variation between duplicate injections for each of a laboratory's three sample extractions to the variation in duplicate injections across all laboratories to identify sample extractions for which variation among duplicate injections was significantly greater than the others. After these outliers were excluded, data from laboratories for which fewer than four determinations remained were excluded for that sample as well. Using the remaining data, means of the duplicate injections were analyzed to estimate sample mean values, repeatability standard deviation, and reproducibility standard deviation, according to ISO 5725-2.

ISO 5725-2 provides further procedures for developing models for relating repeatability and reproducibility standard deviations to the sample mean level, where such relationships are consistent with the data. Linear models relating variability to mean level with and without intercepts were fit, as well as an exponential model relating the $\log$ of variability to the $\log$ of the mean, according to ISO 5725-2. These models were then compared across methods and analytes in an effort to identify the model form that seemed to provide an adequate fit in most cases.

To make comparisons among the methods, a two-way analysis of variance on method and sample was conducted to compare the means, repeatability standard deviation, and reproducibility standard deviation. Given the variation in the level of the TSNAs for the various sample types, and to provide homogeneity of variance across samples, the analysis of variance was applied to the log of the sample means, and to coefficients of variation (standard deviation divided by the sample mean), rather than to the untransformed quantities. Pair-wise comparisons among the four methods were made using the Ryan-Einot-Gabriel-Welsch Multiple Range Test (10) implemented in SAS $^{\circledR}$ (SAS Institute, Cary, NC) software, with $p<0.05$ required for significance.

\section{RESULTS AND DISCUSSION}

The final stage of the TSNAs collaborative study was planned to compare results of the two different procedures from the eight different tobacco samples. Given all participants were supplied with the same samples and standards, the results should represent only the differences of the two analytical methods.

\section{Recovery values}

Recoveries (measurement of accuracy) had not been determined for Method 1, or for Method 2 using a chromatographic internal standard, prior to the collaborative studies of the two procedures. Four laboratories agreed to perform recovery studies.

Table 1 gives the recovery results using the two methods described in the Experimental section. Burley, flue-cured and low TSNAs flue-cured tobaccos were analyzed after adding half of, one and two times the amount of TSNAs determined for the samples. The recoveries were averaged based on the three sample types for each TSNA $(n=9)$. The recovery study using Method 1 was performed by two laboratories. The recovery study using Method 2 was performed by two other laboratories. The recovery using Method 2 quantified by external standards gave lower recoveries than those obtained using internal standards. Comparing the recovery results between the two methods using surrogate internal standards, the overall mean of the TSNAs' recoveries, for Method 2 was $99.6 \%$ vs. $92.1 \%$ recovery for Method 1. Overall, the individual TSNA recoveries are $>85 \%$, demonstrating that the accuracy between the two procedures are in the same range.

\section{Outlier removal}

Removal of outlier duplicate injections was performed using Cochran's test, as described above. With this procedure, data from 80 sample extractions were excluded among the four methods, eight samples, and four TSNAs. Of these, 45 came from a single laboratory, while 14 came from a second laboratory. Remaining duplicate values were averaged for analysis according to ISO 5725-2, as described above.

Mandel charts were used to scrutinize the data for outlier laboratories. The Mandel $h$ chart presents normalized means (the Mandel $h$ statistic) to provide a comparison of laboratory means. The bars indicate the normalized sample mean for the eight tobacco types for each laboratory. The inner lines on the chart show the $95 \%$ confidence interval (C.I.) for laboratory means, while the outer lines indicate the $99 \%$ confidence interval. Sample means falling between the $95 \%$ and $99 \%$ confidence intervals are called "straggler" results, while means beyond the $99 \%$ confidence interval are deemed to be outliers.

Figure 5 presents a Mandel $h$ chart for NNN, as measured by Method 1. It shows that for laboratory 10 , five of the eight sample means were outliers and two of the other three were stragglers. With this clear deviation from the other eleven laboratories, it was decided to exclude all NNN data from this laboratory from further statistical analyses. Figure 6 shows similar results for NAB with Method 1 for labora- 


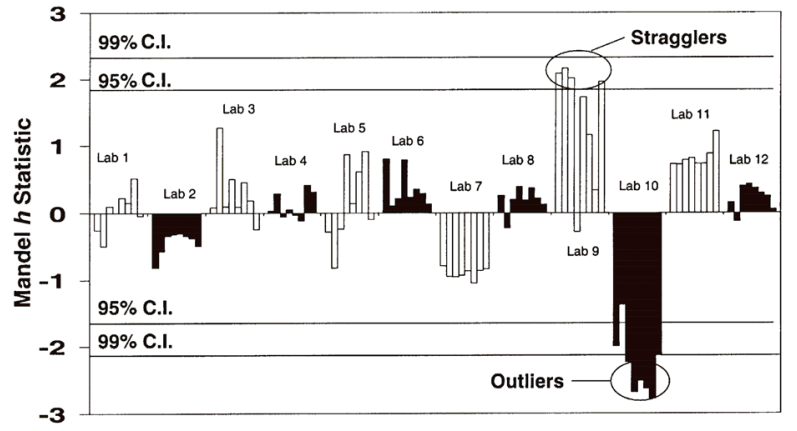

Figure 5. Normalized sample means for the Mandel $\boldsymbol{h}$ statistic by laboratories performing Method 1 for NNN

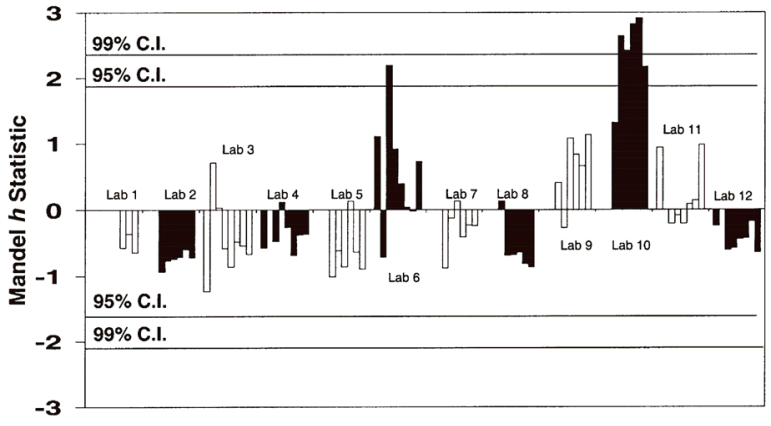

Figure 6. Normalized sample means for the Mandel $\boldsymbol{h}$ statistic by laboratories performing Method 1 for NAB

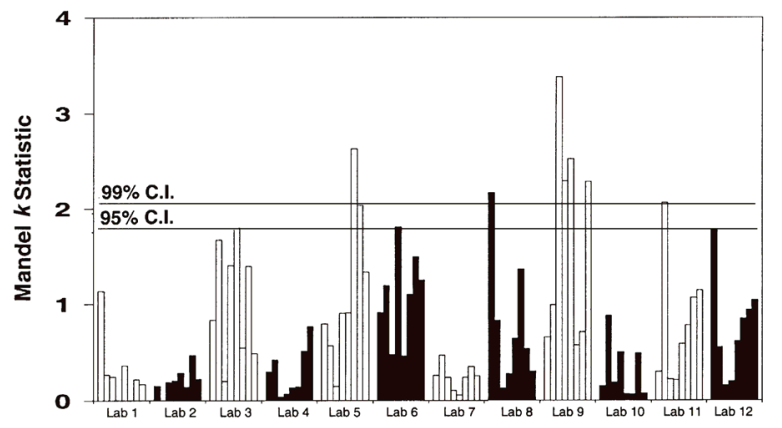

Figure 7. Normalized sample standard deviations for the Mandel $k$ statistic by laboratories performing Method 1 for NNN tory 10 as well, therefore all NAB data from this laboratory were also excluded from further statistical analyses.

Mandel $h$ charts for the three variations of Method 2 did not identify any laboratories with consistent outlier means across samples, so data from all laboratories for Method 2 were used in subsequent analyses.

The Mandel $k$ chart presents normalized standard deviations (the Mandel $k$ statistic) to provide a comparison of within laboratory standard deviations. As for the $h$ chart, the bars indicate the normalized sample standard deviation for the eight tobacco types for each laboratory, while lines on the chart show the upper $95 \%$ and $99 \%$ confidence intervals for within laboratory standard deviations. Again, values falling between the $95 \%$ and $99 \%$ confidence intervals are called "stragglers", while values greater than the $99 \%$ confidence interval are deemed to be outliers.

Figure 7 shows the normalized standard deviation using Method 1 for NNN. The Mandel $k$ normalized statistic graphically depicts the within laboratory variation. While laboratory nine shows standard deviation outliers for four of the eight samples, variation for the other four samples was consistent with the other laboratories, so all data were retained for further analysis. In subsequent analyses, two of these outliers were excluded by Cochran's test.

Mandel $k$ charts were evaluated for all analytes for each method. No outlier laboratories were identified on this basis.

\section{Means, repeatability and reproducibility}

Means, repeatability standard deviation, and reproducibility standard deviation were estimated for each sample, method, and analyte following the procedures recommended in ISO 5725-2. This included sequential application of Cochran's test and Grubbs' test for single outliers and outlier pairs (as directed in the standard). Tables 2 through 5 present the estimated means, repeatability standard deviations (denoted $S_{\mathrm{r}}$ ), and reproducibility standard deviations (denoted $S_{\mathrm{R}}$ ) so obtained, for each analyte. Tables 2 through 5 show that in general, standard deviation estimates increased with the estimated sample mean. Statistical comparisons of the methods across samples were conducted using a two-way analysis of variance on method and sample, followed by the Ryan-Einot-Gabriel-Welsch Multiple Range Test for

Table 2. Mean, repeatability $\left(S_{r}\right)$ and reproducibility standard deviations $\left(S_{R}\right)$ of NNN for each tobacco sample and each analytical method, $\mu \mathrm{g} \mathrm{g}^{-1}$ dry-weight basis ${ }^{\text {a }}$

\begin{tabular}{l|c|c|c|c|c|c|c|c|c|c|c|c}
\hline \multirow{2}{*}{ Sample } & \multicolumn{3}{c|}{ Method 1 } & \multicolumn{3}{c|}{ Method 2 S.I.S. } & \multicolumn{3}{c|}{ Method 2 C.I.S. } & \multicolumn{3}{c}{ Method 2 E.S. } \\
\cline { 2 - 13 } & Mean & $S_{\mathrm{r}}$ & $S_{\mathrm{R}}$ & Mean & $S_{\mathrm{r}}$ & $S_{\mathrm{R}}$ & Mean & $S_{\mathrm{r}}$ & $S_{\mathrm{R}}$ & Mean & $S_{\mathrm{r}}$ & $S_{\mathrm{R}}$ \\
\hline Burley & 8.17 & 0.14 & 0.94 & 9.27 & 0.21 & 0.80 & 8.71 & 0.26 & 0.90 & 8.33 & 0.76 & 2.03 \\
Burley stem & 9.06 & 0.45 & 2.20 & 9.44 & 0.30 & 0.60 & 9.15 & 0.31 & 0.92 & 8.40 & 0.26 & 0.87 \\
Flue-cured & 0.76 & 0.02 & 0.10 & 0.90 & 0.04 & 0.12 & 0.82 & 0.04 & 0.08 & 0.79 & 0.06 & 0.15 \\
1R4F tobacco & 2.10 & 0.07 & 0.28 & 2.45 & 0.04 & 0.23 & 2.38 & 0.05 & 0.22 & 2.30 & 0.12 & 0.33 \\
Composite cigarette tobacco & 2.56 & 0.04 & 0.30 & 2.80 & 0.07 & 0.25 & 2.69 & 0.07 & 0.22 & 2.72 & 0.14 & 0.43 \\
Low TSNA flue-cured & 0.27 & 0.02 & 0.06 & 0.28 & 0.01 & 0.02 & 0.29 & 0.01 & 0.04 & 0.30 & 0.01 & 0.06 \\
Turkish & 0.24 & 0.02 & 0.06 & 0.26 & 0.02 & 0.06 & 0.25 & 0.01 & 0.04 & 0.25 & 0.01 & 0.05 \\
Reference snuff & 3.20 & 0.06 & 0.49 & 3.41 & 0.11 & 0.37 & 3.41 & 0.10 & 0.40 & 3.12 & 0.14 & 0.36 \\
\hline
\end{tabular}

${ }^{a}$ Abbreviations: S.I.S. = surrogate internal standard; C.I.S. = chromatographic internal standard; E.S. = external standard. 
Table 3. Mean, repeatability $\left(S_{r}\right)$ and reproducibility standard deviations $\left(S_{R}\right)$ of NAT for each tobacco sample and each analytical method, $\mu \mathrm{g} \mathrm{g}^{-1}$ dry-weight basis ${ }^{\text {a }}$

\begin{tabular}{|c|c|c|c|c|c|c|c|c|c|c|c|c|}
\hline \multirow[b]{2}{*}{ Sample } & \multicolumn{3}{|c|}{ Method 1} & \multicolumn{3}{|c|}{ Method 2 S.I.S. } & \multicolumn{3}{|c|}{ Method 2 C.I.S. } & \multicolumn{3}{|c|}{ Method 2 E.S. } \\
\hline & Mean & $S_{\mathrm{r}}$ & $S_{R}$ & Mean & $S_{\mathrm{r}}$ & $S_{\mathrm{R}}$ & Mean & $S_{\mathrm{r}}$ & $S_{R}$ & Mean & $S_{\mathrm{r}}$ & $S_{R}$ \\
\hline Burley & 4.06 & 0.08 & 0.25 & 4.60 & 0.08 & 0.35 & 4.36 & 0.09 & 0.24 & 4.23 & 0.41 & 0.79 \\
\hline Burley stem & 2.84 & 0.16 & 0.24 & 3.30 & 0.12 & 0.44 & 3.08 & 0.13 & 0.28 & 2.86 & 0.10 & 0.33 \\
\hline Flue-cured & 1.02 & 0.02 & 0.10 & 1.23 & 0.04 & 0.15 & 1.06 & 0.09 & 0.11 & 1.03 & 0.07 & 0.19 \\
\hline 1R4F tobacco & 1.74 & 0.06 & 0.12 & 2.10 & 0.04 & 0.13 & 2.04 & 0.04 & 0.11 & 2.04 & 0.10 & 0.28 \\
\hline Composite cigarette tobacco & 2.02 & 0.04 & 0.14 & 2.18 & 0.05 & 0.14 & 2.12 & 0.07 & 0.12 & 2.19 & 0.11 & 0.21 \\
\hline Low TSNA flue-cured & 0.41 & 0.03 & 0.07 & 0.47 & 0.03 & 0.07 & 0.44 & 0.02 & 0.03 & 0.46 & 0.03 & 0.09 \\
\hline Turkish & 0.12 & 0.02 & 0.06 & 0.12 & 0.02 & 0.06 & 0.12 & 0.01 & 0.07 & 0.13 & 0.01 & 0.06 \\
\hline Reference snuff & 2.84 & 0.05 & 0.28 & 3.16 & 0.11 & 0.34 & 3.09 & 0.09 & 0.25 & 2.88 & 0.12 & 0.40 \\
\hline
\end{tabular}

${ }^{\text {a }}$ Abbreviations: S.I.S. = surrogate internal standard; C.I.S. = chromatographic internal standard; E.S. $=$ external standard.

Table 4. Mean, repeatability $\left(S_{r}\right)$ and reproducibility standard deviations $\left(S_{R}\right)$ of NAB for each tobacco sample and each analytical method, $\mu \mathbf{g ~ g}^{-1}$ dry-weight basis ${ }^{\text {a }}$

\begin{tabular}{|c|c|c|c|c|c|c|c|c|c|c|c|c|}
\hline \multirow[b]{2}{*}{ Sample } & \multicolumn{3}{|c|}{ Method 1} & \multicolumn{3}{|c|}{ Method 2 S.I.S. } & \multicolumn{3}{|c|}{ Method 2 C.I.S. } & \multicolumn{3}{|c|}{ Method 2 E.S. } \\
\hline & Mean & $S_{\mathrm{r}}$ & $S_{R}$ & Mean & $S_{\mathrm{r}}$ & $S_{\mathrm{R}}$ & Mean & $S_{\mathrm{r}}$ & $S_{R}$ & Mean & $S_{\mathrm{r}}$ & $S_{R}$ \\
\hline Burley & 0.21 & 0.02 & 0.04 & 0.23 & 0.01 & 0.04 & 0.23 & 0.02 & 0.06 & 0.22 & 0.02 & 0.05 \\
\hline Burley stem & 0.14 & 0.01 & 0.04 & 0.18 & 0.01 & 0.04 & 0.16 & 0.01 & 0.06 & 0.14 & 0.01 & 0.06 \\
\hline Flue-cured & 0.10 & 0.01 & 0.07 & 0.17 & 0.01 & 0.11 & 0.13 & 0.01 & 0.09 & 0.14 & 0.02 & 0.10 \\
\hline 1R4F tobacco & 0.09 & 0.01 & 0.03 & 0.13 & 0.01 & 0.05 & 0.14 & 0.01 & 0.04 & 0.14 & 0.01 & 0.04 \\
\hline Composite cigarette tobacco & 0.12 & 0.01 & 0.04 & 0.14 & 0.01 & 0.05 & 0.15 & 0.01 & 0.04 & 0.14 & 0.01 & 0.04 \\
\hline Low TSNA flue-cured & 0.04 & 0.00 & 0.01 & 0.05 & 0.01 & 0.03 & 0.05 & 0.01 & 0.04 & 0.07 & 0.01 & 0.02 \\
\hline Turkish & 0.03 & 0.01 & 0.02 & 0.05 & 0.01 & 0.02 & 0.06 & 0.01 & 0.04 & 0.06 & 0.01 & 0.02 \\
\hline Reference snuff & 0.19 & 0.02 & 0.04 & 0.22 & 0.01 & 0.04 & 0.22 & 0.01 & 0.06 & 0.20 & 0.01 & 0.04 \\
\hline
\end{tabular}

${ }^{\text {a }}$ Abbreviations: S.I.S. = surrogate internal standard; C.I.S. = chromatographic internal standard; E.S. $=$ external standard.

Table 5. Mean, repeatability $\left(S_{\mathrm{r}}\right)$ and reproducibility standard deviations $\left(S_{\mathrm{R}}\right)$ of NNK for each tobacco sample and each analytical method, $\mu \mathrm{g} \mathrm{g}^{-1}$ dry-weight basis ${ }^{\text {a }}$

\begin{tabular}{|c|c|c|c|c|c|c|c|c|c|c|c|c|}
\hline \multirow[b]{2}{*}{ Sample } & \multicolumn{3}{|c|}{ Method 1} & \multicolumn{3}{|c|}{ Method 2 S.I.S. } & \multicolumn{3}{|c|}{ Method 2 C.I.S. } & \multicolumn{3}{|c|}{ Method 2 E.S. } \\
\hline & Mean & $S_{\mathrm{r}}$ & $S_{R}$ & Mean & $S_{\mathrm{r}}$ & $S_{\mathrm{R}}$ & Mean & $S_{\mathrm{r}}$ & $S_{R}$ & Mean & $S_{\mathrm{r}}$ & $S_{R}$ \\
\hline Burley & 0.67 & 0.03 & 0.15 & 0.69 & 0.02 & 0.10 & 0.62 & 0.02 & 0.11 & 0.69 & 0.06 & 0.15 \\
\hline Burley stem & 1.19 & 0.08 & 0.46 & 1.11 & 0.07 & 0.16 & 1.09 & 0.08 & 0.18 & 1.05 & 0.08 & 0.17 \\
\hline Flue-cured & 1.56 & 0.03 & 0.36 & 1.80 & 0.08 & 0.28 & 1.62 & 0.14 & 0.26 & 1.57 & 0.10 & 0.39 \\
\hline 1R4F tobacco & 0.98 & 0.05 & 0.22 & 1.08 & 0.03 & 0.14 & 1.04 & 0.04 & 0.11 & 1.08 & 0.07 & 0.22 \\
\hline Composite cigarette tobacco & 1.31 & 0.05 & 0.31 & 1.35 & 0.03 & 0.16 & 1.31 & 0.04 & 0.14 & 1.39 & 0.06 & 0.24 \\
\hline Low TSNA flue-cured & 0.28 & 0.02 & 0.07 & 0.28 & 0.02 & 0.07 & 0.28 & 0.02 & 0.07 & 0.30 & 0.02 & 0.06 \\
\hline Turkish & 0.10 & 0.01 & 0.09 & 0.07 & 0.01 & 0.03 & 0.07 & 0.01 & 0.06 & 0.09 & 0.00 & 0.02 \\
\hline Reference snuff & 1.11 & 0.03 & 0.28 & 1.24 & 0.04 & 0.21 & 1.21 & 0.03 & 0.16 & 1.13 & 0.09 & 0.19 \\
\hline
\end{tabular}

${ }^{a}$ Abbreviations: S.I.S. = surrogate internal standard; C.I.S. = chromatographic internal standard; E.S. = external standard.

making pair-wise comparisons among the four methods ( $p<0.05$ required for significance). In order to more equally weight the different sample means between the tobacco types and to provide homogeneity of variance across samples, the $\log$ of the means were analyzed to compare the average nitrosamine levels determined by each method. Similarly, the coefficients of variation of repeatability and reproducibility (standard deviations divided by the mean) were analyzed rather than the standard deviation estimates themselves to more equally weight the different samples (because the measures of variation increased with increasing mean levels), and to provide homogeneity of variance.
Table 6 presents mean levels across samples for the four methods, including the transformed or calculated measures used in the statistical analysis, while Figures 8 through 10 present these results graphically. Figure 8 presents the average of the $\log$ of sample means for each method, in units of 10 times $\log$ (ng g $\mathrm{g}^{-1}$ dry weight). In Figure 8, bars that are connected with solid lines are not significantly different from each other while a dotted line indicates that the methods on either end of the connecting line are not significantly different. Thus, Figure 8 shows that NNN means for Method 2 internal standard determinations were significantly greater on average than those for Method 1, 
Table 6. Summary measures of method mean and variability across samples $^{\text {a }}$

\begin{tabular}{|c|c|c|c|c|c|}
\hline Analyte & Measure $^{\mathrm{b}}$ & Method 1 & $\begin{array}{c}\text { Method } 2 \\
\text { S.I.S. } \\
\end{array}$ & $\begin{array}{l}\text { Method } 2 \\
\text { C.I.S. } \\
\end{array}$ & \begin{tabular}{|c} 
Method 2 \\
E.S.
\end{tabular} \\
\hline \multirow[t]{6}{*}{ NNN } & Mean & 3.30 & 3.60 & 3.46 & 3.28 \\
\hline & $S_{r}$ & 0.10 & 0.10 & 0.11 & 0.19 \\
\hline & $S_{\mathrm{R}}$ & 0.55 & 0.31 & 0.35 & 0.53 \\
\hline & Log(Mean) & 2.22 & 2.27 & 2.25 & 2.24 \\
\hline & $\mathrm{CV}_{\mathrm{r}}$ & 3.9 & 3.6 & 3.6 & 5.5 \\
\hline & $\mathrm{CV}_{\mathrm{R}}$ & 17.1 & 10.8 & 11.0 & 17.0 \\
\hline \multirow[t]{6}{*}{ NAT } & Mean & 1.88 & 2.15 & 2.04 & 1.98 \\
\hline & $S_{r}$ & 0.06 & 0.06 & 0.07 & 0.12 \\
\hline & $S_{\mathrm{R}}$ & 0.16 & 0.21 & 0.15 & 0.30 \\
\hline & Log(Mean) & 2.09 & 2.15 & 2.12 & 2.12 \\
\hline & $\mathrm{CV}_{\mathrm{r}}$ & 5.1 & 4.3 & 4.7 & 6.3 \\
\hline & $\mathrm{CV}_{\mathrm{R}}$ & 14.6 & 15.0 & 13.3 & 19.4 \\
\hline \multirow[t]{6}{*}{ NAB } & Mean & 0.12 & 0.15 & 0.14 & 0.14 \\
\hline & $S_{r}$ & 0.01 & 0.01 & 0.01 & 0.01 \\
\hline & $S_{\mathrm{R}}$ & 0.04 & 0.05 & 0.05 & 0.05 \\
\hline & Log(Mean) & 0.98 & 1.11 & 1.10 & 1.11 \\
\hline & $\mathrm{CV}_{\mathrm{r}}$ & 12.6 & 9.5 & 9.2 & 10.6 \\
\hline & $\mathrm{CV}_{\mathrm{R}}$ & 37.7 & 38.5 & 44.3 & 36.4 \\
\hline \multirow[t]{6}{*}{ NNK } & Mean & 0.90 & 0.95 & 0.90 & 0.91 \\
\hline & $S_{\mathrm{r}}$ & 0.04 & 0.04 & 0.05 & 0.06 \\
\hline & $S_{\mathrm{R}}$ & 0.24 & 0.14 & 0.13 & 0.18 \\
\hline & Log(Mean) & 1.84 & 1.84 & 1.82 & 1.84 \\
\hline & $\mathrm{CV}_{\mathrm{r}}$ & 5.1 & 5.5 & 6.0 & 6.5 \\
\hline & $\mathrm{CV}_{\mathrm{R}}$ & 34.1 & 20.0 & 23.5 & 20.0 \\
\hline
\end{tabular}

${ }^{\text {a }}$ Abbreviations: S.I.S. = surrogate internal standard; C.I.S. $=$ chromatographic internal standard; E.S. = external standard.

${ }^{\mathrm{b}}$ Mean $=$ Average analyte determination $\left(\mu \mathrm{g} \mathrm{mg}{ }^{-1}\right.$ dry $) ; S_{\mathrm{r}}=$ repeatability standard deviation; $S_{\mathrm{R}}=$ reproducibility standard deviation; $\log ($ Mean $)=$ average $\log ($ Mean) analyte determination $\left(\mathrm{ng} \mathrm{mg}{ }^{-1}\right.$ dry $\left.\times 10\right) ; \mathrm{CV}_{\mathrm{r}}=$ repeatability coefficient of variation; $\mathrm{CV}_{\mathrm{B}}$ $=$ reproducibility coefficient of variation.

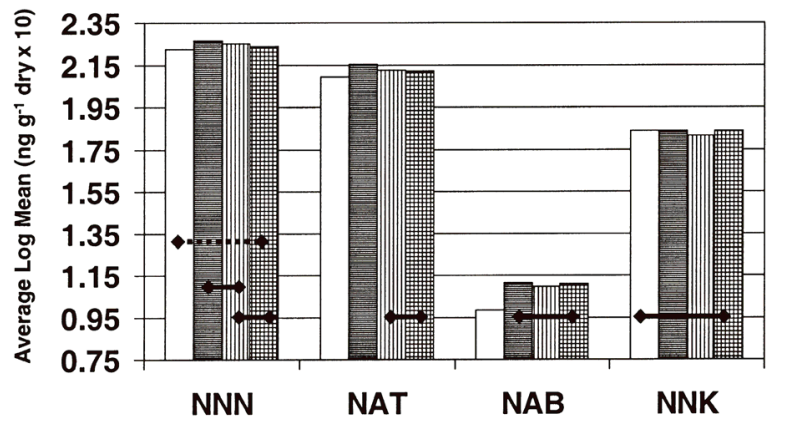

$\square$ Method 1 圆 Method 2 S.I.S. m Method 2 C.I.S. 䧃 Method 2 E.S

Figure 8. Method means comparisons for TSNAs

with increases from $7 \%$ to $10 \%$ in the untransformed TSNA averages for the method determinations among the tobacco types. In addition, NNN means for Method 2 using the surrogate internal standard were significantly greater than those obtained by using Method 2 with an external standard. NAT mean values were significantly higher for Method 2 than for Method 1, with increases from $7 \%$ to $14 \%$ in the untransformed TSNA averages for the method determinations among the tobacco types. In addition, NAT

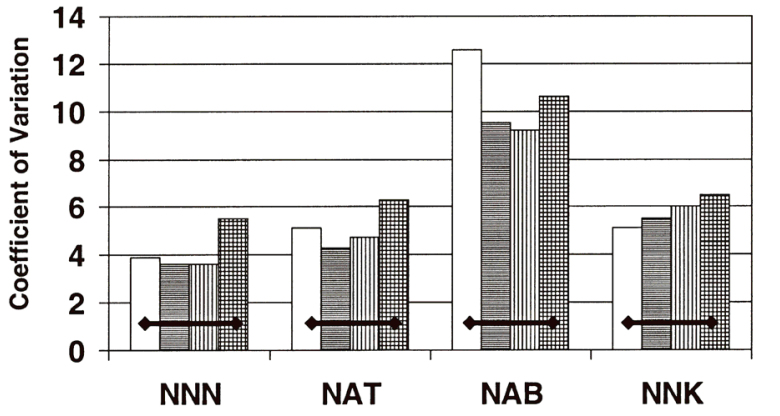

$\square$ Method 1 目 Method 2 S.I.S. 四 Method 2 C.I.S. 田 Method 2 E.S.

Figure 9. Method repeatability comparisons for TSNAs using coefficient of variation

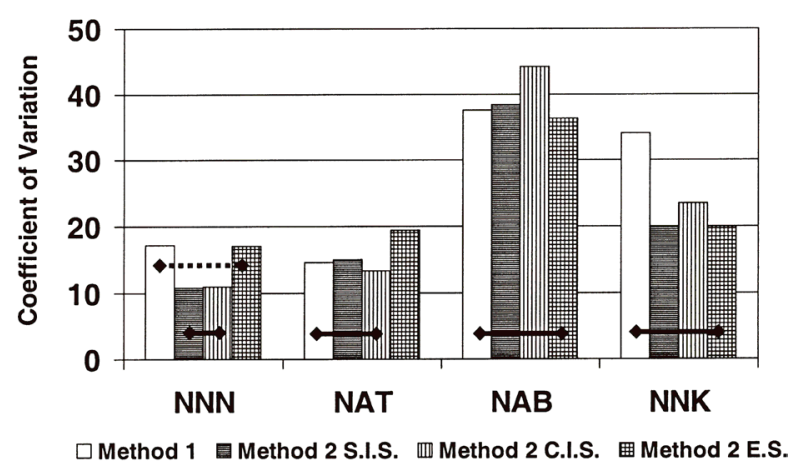

Figure 10. Method reproducibility comparisons for TSNAs using coefficient of variation

mean values for Method 2 with the surrogate internal standard were significantly greater than those obtained by using Method 2 with either the chromatographic internal standard or an external standard. For NAB, mean values were significantly greater for Method 1 than for Method 2 with either internal or external standards, with increases from $30 \%$ to $35 \%$ in the untransformed TSNA averages for the method determinations among the tobacco types. For $\mathrm{NNK}$, none of the methods varied significantly as shown by the solid line connecting all four bars.

Figure 9 presents statistical comparisons of the average repeatability (within laboratory) coefficient of variation, indicating that none of the methods were significantly different from each other. NAB has the highest repeatability coefficient of variation of the TSNAs since it is found in the lowest quantities and, thereby, less easily detected.

Figure 10 presents statistical comparisons of the average reproducibility (between laboratories) coefficient of variation and shows that for NNN, the average reproducibility coefficient of variation was greater using Method 1 than for Method 2 internal standard determinations by six percentage units (17\% vs. 11\%). However, Method 1 reproducibility coefficient of variation was not significantly different from Method 2 using an external standard when analyzing for NNN.

The reproducibility coefficients of variation for NAT using Method 1 and Method 2 using internal standards were not significantly different from each other, but using Method 2 with external calibration resulted in significantly greater 
Table 7. Functional relationships between precision values and the mean level - linear models with intercept ${ }^{\text {a }}$

\begin{tabular}{|c|c|c|c|c|c|c|c|c|c|c|c|c|c|}
\hline \multirow[b]{2}{*}{ Analyte } & \multirow[b]{2}{*}{ Measure $^{b}$} & \multicolumn{3}{|c|}{ Method 1} & \multicolumn{3}{|c|}{ Method 2 S.I.S. } & \multicolumn{3}{|c|}{ Method 2 C.I.S. } & \multicolumn{3}{|c|}{ Method 2 E.S. } \\
\hline & & Int. & Slope & $R^{2}$ & Int. & Slope & $R^{2}$ & Int. & Slope & $R^{2}$ & Int. & Slope & $R^{2}$ \\
\hline \multirow[t]{2}{*}{ NNN } & $S_{\mathrm{r}}$ & 0.009 & 0.025 & 0.838 & 0.009 & 0.025 & 0.956 & 0.006 & 0.029 & 0.936 & -0.001 & 0.057 & 0.913 \\
\hline & $S_{\mathrm{R}}$ & 0.019 & 0.145 & 0.926 & 0.018 & 0.086 & 0.929 & 0.013 & 0.094 & 0.987 & 0.014 & 0.153 & 0.937 \\
\hline \multirow[t]{2}{*}{ NAT } & $S_{\mathrm{r}}$ & 0.018 & 0.021 & 0.826 & 0.013 & 0.022 & 0.942 & 0.010 & 0.031 & 0.827 & 0.006 & 0.054 & 0.904 \\
\hline & $S_{\mathrm{R}}$ & 0.049 & 0.057 & 0.974 & 0.044 & 0.077 & 0.936 & 0.048 & 0.047 & 0.916 & 0.042 & 0.123 & 0.960 \\
\hline \multirow[t]{2}{*}{ NAB } & $S_{\mathrm{r}}$ & 0.006 & 0.040 & 0.918 & 0.009 & 0.010 & 0.947 & 0.006 & 0.039 & 0.918 & 0.006 & 0.051 & 0.934 \\
\hline & $S_{\mathrm{R}}$ & 0.014 & 0.199 & 0.860 & 0.022 & 0.194 & 0.871 & 0.038 & 0.104 & 0.895 & 0.011 & 0.272 & 0.856 \\
\hline \multirow[t]{2}{*}{ NNK } & $S_{\mathrm{r}}$ & 0.006 & 0.036 & 0.900 & 0.008 & 0.032 & 0.913 & 0.004 & 0.048 & 0.861 & -0.003 & 0.073 & 0.968 \\
\hline & $S_{\mathrm{R}}$ & 0.057 & 0.200 & 0.934 & 0.028 & 0.121 & 0.982 & 0.045 & 0.098 & 0.975 & 0.002 & 0.196 & 0.981 \\
\hline
\end{tabular}

${ }^{\text {a }}$ Abbreviations: S.I.S. = surrogate internal standard; C.I.S. = chromatographic internal standard; E.S. $=$ external standard; Int. = model intercept.

${ }^{\mathrm{b}} S_{\mathrm{r}}=$ repeatability standard deviation; $S_{\mathrm{R}}=$ reproducibility standard deviation.

Table 8. Limit of detection and limit of quantitation for TSNAs using Method 1 and Method $2^{\text {a }}$

\begin{tabular}{|c|c|c|c|c|c|c|c|c|c|}
\hline \multirow[b]{2}{*}{ Method } & \multirow[b]{2}{*}{ Method of quantification } & \multicolumn{4}{|c|}{ Limit of detection $\left(\mu \mathrm{g} \mathrm{mL}^{-1}\right)^{\mathrm{b}}$} & \multicolumn{4}{|c|}{ Limit of quantitation $\left(\mu \mathrm{g} \mathrm{mL}^{-1}\right)^{\mathrm{c}}$} \\
\hline & & NNN & NAT & NAB & NNK & NNN & NAT & NAB & NNK \\
\hline 1 & NDHA S.I.S. & 0.04 & 0.04 & 0.05 & 0.04 & 0.14 & 0.12 & 0.16 & 0.14 \\
\hline 2 & E.S. & 0.09 & 0.09 & 0.10 & 0.10 & 0.31 & 0.31 & 0.32 & 0.32 \\
\hline 2 & NG S.I.S. & 0.02 & 0.03 & 0.03 & 0.03 & 0.07 & 0.09 & 0.09 & 0.10 \\
\hline 2 & NDHA C.I.S. & 0.03 & 0.02 & 0.04 & 0.04 & 0.11 & 0.08 & 0.14 & 0.14 \\
\hline
\end{tabular}

${ }^{\text {a }}$ Abbreviations: S.I.S. = surrogate internal standard; C.I.S. = chromatographic internal standard; E.S. = external standard.

b Three times the standard deviation of the lowest standard ran as a sample over several days.

${ }^{c}$ Ten times the standard deviation of the lowest standard ran as a sample over several days.

reproducibility coefficient of variation than for any of the other methods. For NAB and NNK, reproducibility coefficients of variation between laboratories were not significantly different among the different analysis or calibration methods. Again, NAB has the highest reproducibility coefficient of variation due to the small amount found in these tobacco samples. And while Figure 10 shows that a much larger mean reproducibility coefficient of variation was observed using Method 1 to determine NNK, (12 percentage units higher), the methods were not statistically significantly different.

Overall, a greater reproducibility coefficient of variation was found for Method 2 with an external standard for both NNN and NAT, making it a less attractive option. Similarly, Method 1 had a greater reproducibility coefficient of variation for NNN than Method 2 using internal standards, in combination with lower mean levels for NNN, NAT, and NAB than for Method 2 using internal standards. While it is not established that the lower mean levels for Method 1 would indicate a problem, the fact that reproducibility coefficient of variation for Method 2 using a chromatographic internal standard is not significantly greater than that of any other method, combined with its mean levels falling in the middle of the four methods for all four analytes makes it a reasonable choice if a single method is to be selected. In addition to the comparisons described above, functional relationships between precision values and the mean level were evaluated for each analyte for each method, as directed in ISO 5725-2. Table 7 presents the slope and intercept coefficients for models fit to relate repeatability and reproducibility standard deviations to the mean level. In addition, $R$-squared values for the weighted regression models are presented.

\section{Limit of detection and limit of quantitation}

Further analyses were conducted by the participating laboratories to determine, the limit of detection (LOD) and limit of quantitation (LOQ) for the two procedures. The LOD was defined as three times the standard deviation of the lowest standard run as a sample over different days and the LOQ as 10 times the same standard deviation. Typically, about 20 analyses of the lowest standard were determined over four days. Table 8 shows the LOD and LOQ values. Method 2 using the NG surrogate internal standard yielded lower LOD and LOQ than Method 1 using the NDHA surrogate internal standard. Method 2 using external calibration standards gave the highest LOD and LOQ values.

\section{CONCLUSIONS}

Both Method 1 and Method 2 are applicable to a variety of tobacco types and tobacco products. The accuracy of the two methods as determined by the recovery studies using surrogate internal standards, showed a higher recovery for Method 2, averaging 99.6\%, vs. Method 1 which averaged 
92.1\%. Using ISO Standard 5725 guidelines to determine the repeatability and reproducibility of each method, repeatability was not different between the two methods. The coefficient of variation for Method 2 reproducibility was $6 \%$ lower for NNN and numerically $12 \%$ lower for NNK, providing evidence for the TSRC-AMC selection of Method 2 over Method 1.

\section{ACKNOWLEDGEMENTS}

The authors of this publication wish to thank and acknowledge the study participants for their work and efforts in the first phase - collaborative study, second phase - method selection and third phase - collaborative study. Participants were as follows:

Hubert Klus, Helmut Begutter and Anton Pachinger, Austria Tabak; Rickard B. Lucke and Nadia H. Moore, Battelle Toxicology Northwest; Christine A. Rouse and C. Roy Taylor, Brown \& Williamson Tobacco Corporation; Miguel Gonzalez and Cecilia Heit, Dimon International, Inc.; Andre Fouquet, Health Canada; Jacques Dumont, Imperial Tobacco Limited; Takeshi Sakaki, Hideyuki Tomita, Hideki Takahashi and Hitoshi Saito, Japan Tobacco Inc.; Bill Rickert, Mehran Sharifi and Peter Joza, Labstat International, Inc.; Richard Entz, Christina Hoffman and Richard Shober, Lancaster Laboratories; Jim Morgan and Cynthia Williard, Lorillard Tobacco Company; Jean-Marc Renaud and Roxanne Boudoux, Philip Morris International; Szu-Sung Yang and Chorng Huang, Philip Morris USA; Mike Borgerding, Ruthie Farmer, Christy Fishel, Bill Clapp, Pat Martin and Angela Synder, R.J. Reynolds Tobacco Company R\&D; Mike Edwards and Herbert Copeland, R.J. Reynolds Tobacco Company AVOCA Division; Mark Hathaway, Kim Baughman and Ken Boyer, Southern Testing \& Research Laboratories; Lennart Johansson and Susanne Back, Swedish Match North Europe Division; Astor Green and Steve Terrell, Swedish Match North American Division; Thomas Losty, John Townend, Paul Moser and Ahad Majeed, Swisher International, Inc.; Rusty Owen, Jim Franke and Sumitra Balasubramanian, U.S. Smokeless Tobacco Manufacturing LP; Naewanna Dye, University of Kentucky.

\section{REFERENCES}

1. Lucke, R.B., H.A. Moore, and R.B. Westerberg: Determination of TSNA's from tobacco filler by liquid chromatography mass spectrometry/mass spectrometry; Presentation No. 53 at $54^{\text {th }}$ Tobacco Science Research Conference, September 24-27, 2000, Nashville, TN.

2. Risner, C.H. and F.W. Wendelboe: Quantification of tobacco specific nitrosamines in tobacco; Tob. Sci. 38 (1994) 1-6.
3. Spiegelhalder, B., S.J. Kubacki, and S. Fisher: A method for the determination of tobacco-specific nitrosamines (TSNA), nitrate and nitrite in tobacco leaves and processed tobacco; Beitr. Tabakforsch. Int. 14 (1989) 135-144.

4. Prokopczyk, B., D. Hoffmann, J.E. Cox, M.V. Djordjevic, and K.D. Brunnemann: Supercritical fluid extraction in the determination of tobacco-specific $\mathrm{N}$ nitrosamines in smokeless tobacco; Chem. Res. Toxicol 5 (1992) 336-340.

5. Prokopczyk, B., M. Wu, J.E. Cox, S. Amin, D. Desai, A.M. Idris, and D. Hoffmann: Improved methodology for the quantitative assessment of tobacco-specific $N$ nitrosamines in tobacco by supercritical fluid extraction; J. Agric. Food Chem. 43 (1995) 916-922.

6. Sharma, A.K., B. Prokopczyk, and D. Hoffmann: Supercritical fluid extraction of moist snuff; J. Agric. Food Chem. 39 (1991) 508-511.

7. Bennett, C.B., C.H. Midgett, K.S. Johnston, J.K. Owen, J.C. Welden, S.M. Shanmugan, J.E. Franke, and S. Balasubramanian: An automated analytical method for determination of tobacco specific nitrosamines in tobacco; Smoke Science and Product Technology Presentation No. 33 at 2002 CORESTA Congress, September 22-27, 2002, New Orleans, LA.

8. Risner, C.H., J.B. Reece, and W.T. Morgan: The determination of tobacco specific nitrosamines in tobacco: A collaborative investigation of current methodology; in: Recent Advances in the Reduction of Tobacco-Specific Nitrosamines in Leaf and Smoke, Proceedings of a Symposium Presented at the $55^{\text {th }}$ Meeting of the Tobacco Chemists' Research Conference, Rec. Adv. Tob. Sci. 27 (2001) 47-73.

9. ISO 5725-2: 1994(E): Accuracy (trueness and precision) of measurement methods and results - Part 2: Basic method for the determination of repeatability and reproducibility of a standard measurement method, International Organization for Standardization, Geneva Switzerland, 1994.

10. Einot, I. and K.R Gabriel: A Study of the powers of several methods of multiple comparisons; J. Am. Statistical Assoc. 70 (1975) 351.

Address for correspondence:

Charles H. Risner

R.J. Reynolds Tobacco Company

Winston-Salem, North Carolina 27102

USA

E-mail:RisnerC@RJRT.com 